\title{
A DELAÇAOO PREMIADA E O PROCESSO PENAL COMO MERCADO DE COMPRA E VENDA DE INFORMAÇÕES
}

\author{
PLEA BARGAIN AND CRIMINAL PROCEDURE AS A MARKET FOR THE PURCHASE AND \\ SALE OF INFORMATION
}

\section{LA DELACIÓN PREMIADA Y EL PROCESO PENAL COMO MERCADO DE COMPRA Y VENTA DE INFORMACIONES}

\section{Alexandre Morais da Rosa ${ }^{1}$}

\section{Raquel Mazzuco Sant'Ana²}

Licença CC BY:

Artigo distribuído sob os termos Creative Commons, permite uso e distribuição irrestrita em qualquer meio desde que o autor credite a fonte original.

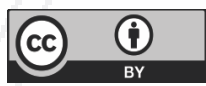

\begin{abstract}
Resumo: O presente artigo tem como objetivo analisar a delação premiada e a sua evolução no ordenamento jurídico brasileiro, em paralelo ao contexto da justiça negocial que permite a compreensão do mercado penal. Assim, por meio da utilização da barganha, aponta-se a existência de um processo penal negociado, cujas regras e parâmetros são diferentes do processo tradicional. Para tanto, tratar-se-á sobre a relação custo-benefício, bem como a ampliação do uso impactante da delação premiada, com a proposta de modulação do mapa-mental preexistente para compreender o instituto no mercado de compra e venda de informações. No entanto, é necessário apontar os limites democráticos ao modelo importado e vislumbrar a sua compatibilidade com o regime atual de construção da verdade.
\end{abstract}

Palavras-chave: Delação premiada; processo penal; justiça negocial; mercado; democracia.

Abstract: This article analyzes the institute of plea bargain and its evolution in the Brazilian legal system, alongside the context of transactional justice, which allows a deeper understanding of the "penal market". Thus, through the use of the concept of "bargain", the existence of a negotial criminal procedure is exposed, and it becomes clear that its rules and parameters are different from those of the traditional procedures. For this analysis, a cost-benefit analysis is carried out, as well as an expansion on the impacting use of the plea bargain, proposing a modulation of the preexisting mind map used to understand the institute of bargaining in the information trade market. It is, however, necessary to single out the democratic limits imposed upon the imported model, and foresee its compatibility with the current regime of truth-building.

$\overline{1}$ Juiz de Direito (TJSC). Professor da UFSC e da UNIVALI. Doutor em Direito. E-mail: alexandremoraisdarosa@ gmail.com

2 Doutoranda em Direito pela Universidade Federal de Santa Catarina - UFSC. Advogada (OAB/SC 41.793). E-mail: raquel@mnadvocacia.com.br. 
Key-words: plea bargain; criminal procedure; transactional justice; market; democracy.

Resumen: El presente artículo tiene como objetivo analizar la delación premiada y su evolución en el ordenamiento jurídico brasileño, en paralelo al contexto de la justicia negocial que permite la comprensión del mercado penal. Así, por medio de la utilización del acuerdo, se apunta la existencia de un proceso penal negociado, cuyas reglas y parámetros son diferentes del proceso tradicional. Para tanto, se trata sobre la relación costo beneficio, bien como la ampliación del uso impactante de la delación premiada, con la propuesta de modulación del mapa-mental preexistente para comprender el instituto en el mercado de compra y venta de informaciones. Sin embargo, es necesario apuntar los límites democráticos al modelo importado y vislumbrar su compatibilidad con el régimen actual en construcción de la verdad.

Palabras-clave: Delación premiada; proceso penal; justicia negocial; mercado; democracia.

\section{INTRODUÇÃO}

Ao longo dos anos, em tempos de crescente criminalidade organizacional, principalmente envolvendo ofensa aos bens jurídicos do próprio Estado, a delação premiada foi incorporada pelo Poder Legislativo ao ordenamento jurídico como uma recompensa ao delator, a fim de auxiliar nas investigações e para repressão de alguns tipos de crimes, quer diminuindo sua pena, quer extinguindo sua punibilidade ${ }^{3}$.

A delação é um acordo entre Ministério Público e o delator, em que este, em troca de informações, recebe vantagem, as quais podem variar entre uma causa de diminuição da pena a uma excludente de culpabilidade advinda do perdão judicial (art. 13, da Lei n. 9.807/99). Desse modo, pode servir como meio de prova ${ }^{4}$ na persecução penal, ao dar ao investigador indicativos da materialidade e da autoria do delito.

O instituto, que se mostrou eficiente no ordenamento estrangeiro, em países como Itália, Estados Unidos, Alemanha, foi inserido no ordenamento jurídico brasileiro, desde as Ordenações Filipinas, e de modo desordenado, vem ganhando destaque mais recentemente. Está previsto hoje na Lei 12.850/13 (organização criminosa) como mais um instrumento apto ao combate do crime organizado. O Estado, então, utiliza a delação muitas vezes como a solução para limitar o

3 BRITO, Michelle Barbosa de. Delação Premiada: da eficiência à integridade. Belo Horizonte: Editora D’Plácido, 2016, p. 51: "[...] nasceu impulsionada por uma política criminal que busca dar respostas rápidas e eficientes no sentido de satisfazer as demandas sociais por segurança, decorrentes do medo da criminalidade e do sentimento de insegurança que são percebidos subjetivamente, ainda que essa percepção não corresponda, na mesma proporção, à existência objetiva do crime".

4 GAGLIANO, Pablo Stolze. Novo curso de direito civil, volume 1: parte geral. 14. ed. São Paulo: Saraiva, 2012: Lembrando que não poderá servir como prova caso seja o único meio, devendo ser instruído por outras provas as quais confirmem as informações do delator, embora suscetível às manipulações retóricas das decisões judiciais. 
aumento da criminalidade organizada, dando ao colaborador, em troca, benefícios em relação à restrição da sua liberdade e/ou no conteúdo e regime da punição. O presente artigo, no entanto, quer analisar o instituto, para além do seu conceito e da sua expansão legislativa no ordenamento jurídico brasileiro, sob o enfoque do devido processo legal consensual, ou seja, considerando-se a barganha e a negociação entre as partes. O Brasil seguiu a tendência mundial de ampliação dos espaços de consenso no Processo Penal, atendendo, de um lado, a lógica da redução de custos e, de outro, da abreviação das respostas às condutas criminais, em especial, com a adoção de atalhos de assunção e responsabilização penal, muito em decorrência do acompanhamento midiático, dando a aparência de enfrentamento das questões sociais, dentre elas a corrupção.

Nesse contexto é preciso superar o romantismo de querer acomodar as novas técnicas de investigação, os novos mecanismos de negociação, as estratégias de uma guerra processual nos moldes pensados pela modernidade, dado o giro negocial do processo penal transformado em mesa de negociação. Passa-se a analisar, então, o efeito da barganha para reduzir os casos penais, buscando a eficiência do sistema penal, e fornecendo maior capacidade de enfrentamento de processos complexos, com o desafio, no entanto, de respeitar os limites democráticos constitucionais postos.

\section{A DELAÇÃO PREMIADA NO CONTEXTO BRASILEIRO DA JUSTIÇA NEGOCIAL}

A colaboração premiada, gênero da espécie delação premiada, em geral tratada como sinônimos, constitui-se como instrumento de troca (compra e venda de informações) para obtenção de prova, em que o colaborador (investigado ou acusado) coopera efetiva e voluntariamente com a investigação criminal recebendo, em contrapartida, benefícios penais e/ou patrimoniais. Segundo Alexandre Morais da Rosa, a colaboração premiada "é o mecanismo pelo qual o Estado autoriza, no jogo processual, por mecanismo de barganha, o estabelecimento de um 'mercado judicial', pelo qual o colaborador, assistido por um advogado, negocia com o Ministério Público, informações capazes de autoincriminar o agente e carrear elementos probatórios contra terceiros" ${ }^{11}$.

$5 \quad$ ROSA, Alexandre Morais da. Guia do Processo Penal conforme a Teoria dos Jogos. 4. ed. Florianópolis: Empório do Direito, 2017, p. 527. 
Cabe ressaltar sobre a etimologia do termo delação, que tem origem no latim "delatio", de defere, na sua concepção de denunciar, delatar, acusar, deferir. A delação premiada consiste em uma técnica de investigação em que o Estado oferta benefícios àquele que confessar e prestar informações úteis ao esclarecimento do fato delituoso. É mais precisamente chamada "colaboração premiada" - visto que nem sempre dependerá ela de uma delação.

O instituto da delação premiada surgiu no direito estrangeiro, na Itália, a partir de 1970, após foi utilizado na operação "Mãos Limpas"6, cuja finalidade era aniquilar a máfia, em que aquele que aceitava colaborar com as investigações a fim de derruir as organizações criminosas tinha como recompensa a diminuição da reprimenda. Ganhou notoriedade ao ser usada pelo magistrado italiano Giovanni Falcone para desmantelar a máfia e suas articulações com políticos.

Nos Estados Unidos, foi introduzido pela Lei Ricco, nos anos 60 . O instituto era aplicado como um acordo entre o acusado e o Ministério Público (prosecutor), com a posterior redução da pena daquele quando condenado, devendo ser homologada pelo juiz para se tornar efetiva. Muitos julgados proferidos pela Corte Suprema Americana tem servido de respaldo para aplicação do instituto no Brasil, embora usado sem a devida "tropicalização"7, uma vez que vigora nos Estados Unidos o modelo de ação penal da common law, a partir da lógica do plea bargaining ${ }^{8}$.

6 CHEMIN, Rodrigo. Mãos Limpas e Lava Jato: a corrupção se olha no espelho. Porto Alegre: CDG, 2017.

7 LÓPEZ MEDINA, Diego Eduardo. La teoria impura del derecho. Bogotá: Legis, 2004.

8 MAIEROVITCH, Wallter Fanganiello. Apontamentos sobre Política Criminal e a "Plea Bargaining". Revista de Processo, ano 16, n. 62, abr./jun. 1991. p. 91-96. p. 92: "No direito norte-americano, até o ano de 1968 e como instrumento de auto-composição de litígios penais, a bargaining era empregada de maneira oculta, sem publicidade: under the table, conforme os críticos"; ALSCHULER, Albert W. Plea Bargaining and Its History. Law \& Society Review, v. 13, n. 2, Special Issue on Plea Bargaining, 1979; MATHER, Lynn M. Comments on the history of plea bargaining. Law \& Society Review, v. 13, n. 2, Special Issue on Plea Bargaining, 1979; LANGBEIN, John H. Understanding the short history of plea bargaining. Law \& Society Review, v. 13, n. 2, Special Issue on Plea Bargaining, 1979, p. 262-265; LANGER, Máximo. Rethinking Plea Bargaining: The Practice and Reform of Prosecutorial Adjudication in American Criminal Procedure. American Journal of Criminal Law, v. 33, 2006, p. 229; LANGER, Máximo. From Legal Transplants to Legal Translations: The Globalization of Plea Bargaining and the Americanization Thesis in Criminal Procedure. Harvard International Law Journal, v. 45, n. 1, [S.I.]: HARv. INT'L L.J., 2004, p. 1-2; ZYSMAN QUIRÓS, Diego. Castigo e determinação da pena nos E.U.A. Um estudo sobre as United States Sentencing Guidelines. Trad. Jacson Zilio. Florianópolis: Empório do Direito, 2017, p. 48 e sgts. 
O investigado pode, com a assistência de defensor: (a) confessar a culpa (plead guilty); (b) negar a culpa (not guilty); e (c) não se defender (no contest, nolo contendere). Nas hipóteses de confessar e não querer se defender, abre-se caminho para a barganha9.

No Brasil, a delação premiada registrou seus primeiros indícios nas Ordenações Filipinas e também era presente na época ditatorial a fim de descobrir quem estava contra o governo. Mas apenas com a Lei dos Crimes Hediondos $^{10}$ (Lei 8.072/90), com intuito de atender os excluídos e socialmente marginalizados, passou a ser expressamente prevista no nosso ordenamento jurídico. Após, expandiu-se também em alcance da criminalidade organizada (Lei 9.034/95) e dos crimes econômicos ou "crimes de colarinho branco"; atingindo os crimes contra o sistema financeiro nacional, crimes contra a ordem tributária, contra as relações de consumo (Lei 9.080/95); lavagem de dinheiro ou ocultação de bens, direitos e valores (Lei 9.613/98); e, em seguida, passou a ser aplicada para qualquer delito, com o advento da lei que cuida da proteção de vítimas e testemunhas (Lei 9.807/99). Também teve lugar na Lei das infrações contra a ordem econômica (Lei 10.149/00) e na Lei de drogas (Lei 11.343/06).

Posteriormente, com o advento da Lei 12.850/2013, houve um avanço legislativo no sentido de combater as organizações criminosas e expandir o exercício do poder punitivo do Estado, dando algumas balizas, mas com problemas democráticos. "Em um primeiro momento, a delação foi na linguagem forense

9 PHILIPPI, Isabela Ramos. A (im)possibilidade de aplicação da plea bargaining no processo penal brasileiro: uma análise conforme a Constituição da República e a tradição continental. Florianópolis: UFSC (Direito - Monografia), 2010, p. 21: "Genericamente, as aludidas normas definem que acusação e defesa podem debater e chegar a um acordo acerca das acusações. Se, realizado o acordo, o réu declara-se culpado ou nolo contendere quanto ao crime pelo qual está sendo acusado ou por crime menos grave, o acordo deve especificar, em contrapartida, os benefícios oferecidos ao acusado pela promotoria, quais sejam: (A) não alegar ou dispensar outras acusações além daquela(s) já estipuladas; (B) recomendar (ou comprometer-se a não se opor ao requerimento do réu) uma determinada pena apropriada ao caso, a aplicação de uma determinada disposição das Sentencing Guidelines, ou que determinado fator (reincidência, má conduta, dentre outros) não seja aplicado - ressaltando-se que tais recomendações ou requerimentos não vinculam a decisão do magistrado; ou (C) acordar, de maneira específica, os mesmo fatores considerados nas recomendações (quantidade da pena, aplicação de Sentencing Guidelines, etc.), vinculando o magistrado aos termos estabelecidos caso o acordo seja aceito pela corte. Quanto à força vinculativa da plea bargaining, verifica-se que, nos acordos do tipo (A) ou (C), o juiz pode aceitar ou rejeitar o acordo de imediato ou adiar a decisão até a conclusão da análise do presentence report. Já nos acordos do tipo (B), que não vinculam a decisão, o juiz tem o dever de advertir ao réu de que não será permitida a retratação da declaração de culpa após a prolação da sentença que deixar de seguir as recomendações ou requerimentos estabelecidos".

10 Art. $5^{\circ}$, XLIII - a lei considerará crimes inafiançáveis e insuscetíveis de graça ou anistia a prática da tortura, o tráfico ilícito de entorpecentes e drogas afins, o terrorismo e os definidos como crimes hediondos, por eles respondendo os mandantes, os executores e os que, podendo evitá-los, se omitirem; 
mais propriamente para designar a denúncia de um delito, praticado por pessoa, sem que o denunciante (delator) se mostre parte interessada diretamente na sua repressão, feita perante autoridade judiciária ou policial, a quem compete a iniciativa de promover a verificação da denúncia e punição do criminoso"11.

Assim, o Brasil seguiu a tendência mundial de ampliação dos espaços de consenso no Processo Penal, atendendo, de um lado, a lógica da redução de custos e, de outro, da abreviação das respostas às condutas criminais, em especial, com a adoção de atalhos de assunção e responsabilização penal. Dito de outra forma: cada vez mais a atual conjuntura político-econômica estimula a produção e a implementação de mecanismos processuais penais de restrição da liberdade a fim de assegurar à população respostas cada vez mais rápidas e eficientes ${ }^{12}$.

Os impasses instaurados decorrem da necessidade de flexibilização e/ou releitura soft do lugar e da função dos direitos fundamentais, da dignidade da pessoa humana ${ }^{13}$, previstos na Constituição da República e nas Convenções de Direitos Humanos $\left(C R\right.$, art. $5^{\circ}, \S \S 1^{\circ}, 2^{\circ}$ e $\left.3^{\circ}\right)$. Isso porque o papel do Estado é o de efetivar garantias mínimas - respeito às regras - sobre o potencial abuso do poder estatal por seus representantes que, movidos por recompensas individuais, podem se valer de motivações individuais e não públicas. Contudo, a noção de direitos fundamentais ${ }^{14}$ e a possibilidade de disposição sobre o conteúdo de certas normas processuais ${ }^{15}$, em face da inserção da lógica da commow law (custo/ benefício), demandam esforço para compreensão do Mercado penal, por meio da

11 MOSSIN, Heráclito Antonio; MOSSIN, Júlio Cesar O.G. Delação Premiada - aspectos jurídicos. Leme: J. H. Mizuno, 2016, p. 40.

12 MARCELLINO JR., Júlio. MORAIS DA ROSA, Alexandre. O Processo Eficiente Na Lógica Econômica: Desenvolvimento, Aceleração e Direitos Fundamentais. Florianópolis: Empório do Direito, 2015.

13 Para uma discussão interessante: SARLET, Ingo Wolfgang (Org.). Dimensões da dignidade: ensaios de filosofia do direito e direito constitucional. Trad. Ingo Wolfgang Sarlet, Pedro Scherer de Mello Aleixo e Rita Dostal Zanini. Porto Alegre: Livraria do Advogado, 2005; CADEMARTORI, Sérgio. Estado de Direito e Legitimidade: uma abordagem garantista. Porto Alegre: Livraria do Advogado, 1999, p. 161.

14 FERRAJOLI, Luigi. Derechos y garantías. - La ley del más débil. Trad. Perfecto Andres Ibanez. Madrid: Trotta, 1999, p. 23-4: "Los derechos fundamentales se configuran como otros tantos vínculos sustanciales impuestos a la democracia política: vínculos negativos, generados por los derechos de libertad que ninguna mayoria puede violar; vínculos positivos, generados por los derechos sociales que ninguna mayoría puede dejar de satisfacer".

15 FERRAJOLI, Luigi. Derecho y razón. Trad. Perfecto Andres Ibanez. Madrid: Trotta, 2001; Direito e Razão: teoria do garantismo penal. Trad. Ana Paula Zomer et alii. São Paulo: Revista dos Tribunais, 2002; Derechos y garantías - La ley del más débil. Trad. Perfecto Andres Ibanez. Madrid: Trotta, 1999; Los fundamentos de los derechos fundamentales. Trad. Perfecto Andres Ibanez. Madrid: Trotta, 2001; Garantismo: una discusión sobre derecho y democracia. Trad. Andrea Greppi. Madrid: Trotta, 2006; COPETTI NETO, Alfredo. A democracia constitucional sob o olhar do garantismo jurídico. Florianópolis; Empório do Direito, 2016. 
utilização da barganha ${ }^{16}$. Os direitos fundamentais possuem como características teóricas a inalienabilidade, a inegociabilidade e a indisponibilidade. Não são, deste modo, alienáveis, negociáveis e disponíveis, quer por setores privados e, com maior vigor para pretensão deste escrito, pelo "mercado penal", via contratos/ acordos de delação e leniência. Logo, as normas de processo penal eram pensadas, até pouco tempo, como direitos fundamentais, sendo que atualmente se pode falar em regimes especiais, nos quais vigoram a disponibilidade da ação penal e a renúncia ao direito ao processo pelo efeito da autoincriminação. A discussão pela eficácia operativa do que se constitui como standard de garantias e o que pode ser negociado/renunciado, na perspectiva de privilégios, está na ordem do dia, sem que haja um desenho legal e compreensões consolidadas. O standard se apresenta como o delineamento do mínimo de garantias reconhecidas e efetivadas em face da tendência de relativização destas garantias ${ }^{17}$.

O que se passou nos últimos tempos foi o acolhimento de uma nova forma de pensar (mapa mental), em que se deve distinguir, como mostra Garcez ${ }^{18}$, entre estrutura padrão (standard) do Estado, sobre as quais inexiste disponibilidade pelas partes; enquanto direitos conferem privilégios, plenamente renunciáveis pelo titular ${ }^{19}$. Assim é que as normas constitutivas do jogo processual (Jurisdição, órgãos, linhas gerais, etc.) não podem ser renunciadas, porque não são privilégios dos jogadores, enquanto as normas regulativas (processo, procedimento, direitos subjetivos) autorizam que os jogadores disponham da vontade para obtenção de consensos. As normas regulativas imputam direitos disponíveis e com juízos de oportunidade/disponibilidade para os jogadores e transformam a atividade jurisdicional em mecanismo de homologação e controle. As cláusulas de disponibilidade, portanto, inserem mecanismos de barganha e negociação

16 Conferir o precioso trabalho: VASCONCELLOS, Vinícius Gomes de. Barganha e Justiça Criminal Negocial: Análise das tendências de expansão dos espaços de consenso no Processo Penal brasileiro. São Paulo: Ibccrim, 2015.

17 NICOLÁS GARCÍA, Gerardo; ALBERTO JULIANO, Mario; PÉREZ GALIMBERTI, Alfredo. Derecho al mejor derecho y poder punitivo. Buenos Aires: Del Puerto, 2011.

18 RAMOS, João Gualberto Garcez. Curso de processo penal norte-americano. São Paulo: RT, 2006, p. 110-111: "Ao conferir um direito, ou privilégio, ou prerrogativa, ao imputado, reconhecem que um certo mandamento foi concebido no seu estrito interesse. Em outras palavras, reconhecem que o enunciado é programático, que o sistema de justiça criminal pode 'viver' sem o respeito a ele, se for da vontade do imputado dele abrir mão. A essa característica da faculdade, ou direito, se chama de 'desistibilidade' (waivability). [No segundo caso]: "estabelecem um standard, os princípios alicerçam o próprio sistema de justiça criminal. Com isso, o mandamento é absoluto; não pode ser afastado, porque constitui a estrutura do próprio sistema. Se for violado, configurar-se-á uma verdadeira e própria infração ao princípio standard do devido processo legal".

19 ROBLES, Gregorio. As regras do direito e as regras dos jogos: ensaio sobre a teoria analítica do direito. Trad. Pollyana Mayer. São Paulo: Noeses, 2011, p. 12. 


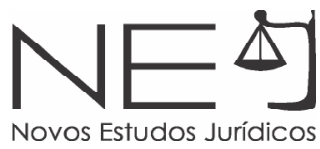

ampliados, tanto sobre o conteúdo da imputação como sobre os efeitos (penas, regimes, etc.) da pena. Após o acolhimento da delação premiada e da leniência, será preciso repensar como se compreende o processo penal. Isso porque falar em princípios do processo penal (Jurisdição, Ação e Processo) sem modular o mapa mental com as novas compreensões gera curto-circuito. Pode-se continuar, por exemplo, a falar que a ação penal é indisponível? Com a Transação Penal da Lei dos Juizados Especiais Criminais já se criou o "jeitinho" da "disponibilidade regrada"20, embora Geraldo Prado ${ }^{21}$ tivesse demonstrado que não cabia na tradição do Direito Continental, da qual, em princípio, se é herdeiro.

No entanto, a invasão do common law e da lógica da eficiência processual é uma realidade. Continuar negando histericamente o modo de adjudicação das decisões em matéria penal é uma posição possível, eticamente louvável, mas incompatível com o regime atual de construções de verdade.

\section{O DESENHO DO JOGO DA DELAÇÃO PREMIADA (BARGANHA) NO MERCADO PENAL}

O êxito da colaboração premiada no Direito dos Estados Unidos pressupõe entender o pano de fundo pragmático (filosófico, de verdades consensuais) e do mercado judicial diante dos custos de manutenção de sistema penal caro e com alta exigência de controle probatório. Com isso, justificado estaria o acolhimento de mecanismos de troca e negociação em face de condutas ilegais. É meio de aceleração, redução de custos, com simplificação procedimental e melhoria da eficiência do Sistema Judicial, já que consegue "produzir" decisões com trânsito em julgado sem a necessidade de julgamentos caros, demorados e custosos 22 .

20 Não se pode falar em obrigatoriedade mitigada, mas sim de disponibilidade. Consultar: ARMENTA DEU, Teresa. Criminalidad de bagatela y principio de oportunidade: Alemania y España. Barcelona: PPU, 1991, 211

21 PRADO, Geraldo. Transação Penal. Coimbra: Almedina, 2015.

22 VASCONCELLOS, Vinícius Gomes de. Barganha e Justiça Criminal Negocial: Análise das tendências de expansão dos espaços de consenso no Processo Penal brasileiro. São Paulo: Ibccrim, 2015, p. 28. 
A barganha ${ }^{23}$, aliás, é inerente à vida econômica e significa novo modo de pensar o Processo Penal ${ }^{24}$. Tentar encaixar a barganha a partir das categorias clássicas do Processo Penal brasileiro é o erro lógico da abordagem. Precisa-se de novos pressupostos de compreensão, especialmente no tocante à distinção entre "direitos fundamentais" e "privilégios", já que a disponibilidade da ação penal e o do direito (e não dever) ao processo serão os pressupostos ao estabelecimento do mercado da barganha. Ainda que a legalidade ${ }^{25}$ presida a atuação estatal, a abertura de espaços de consenso modifica o regime de produção de verdades jurídicas, vinculando-se ao contexto das funções, lugares e poderes dos jogadores/julgadores ${ }^{26}$.

Assim é que, não confundindo "legalidade" com "oportunidade", surgem espaços de negociação ${ }^{27}$ em que a lei autoriza que o titular da ação penal possa negociar com o acusado e seu defensor o enquadramento legal, as penas e o regime de cumprimento. A oportunidade, todavia, deve significar a tomada de decisão sobre cursos de ação, não se confundindo com a plena disponibilidade, incidindo controle jurisdicional dos limites no momento da homologação. O jogo inerente à decisão pressupõe a qualidade e a quantidade de informações capazes de justificar a estratégia dominante, vinculada às recompensas possíveis, em que o mercado de trocas se estabelece.

A oportunidade da ação penal precisa de novas lentes para sua compreensão, já que informado pelo pragmatismo e utilitarismo, diante das recompensas dos agentes processuais. Será necessário inventariar, a partir da Teoria dos Jogos, quem são os jogadores, quais as regras que acolhem, as táticas usuais, a estratégia pretendida e as recompensas, os grupos de pressão, a Teoria do Caso. As expectativas de comportamento decorrem da qualidade e da quantidade de informações que se obtiver da estrutura do contexto. Diante

23 VASCONCELLOS, Vinícius Gomes de. Barganha e Justiça Criminal Negocial: Análise das tendências de expansão dos espaços de consenso no Processo Penal brasileiro. São Paulo: Ibccrim, 2015, p. 68.

24 SCHÜNEMANN, Bernd. ¿Crisis del procedimiento penal? ¿ Marcha triunfal del proceso penal norte-americando en el mundo? In: SCHÜNEMANN, Bernd. Temas actuales y permanentes del derecho penal después del milênio. Madrid: Tecnos, 2002, p. 288-302; COSTA, Eduardo Maia. Princípio da oportunidade: muitos vícios, poucas virtudes. Revista do Ministério Público de Lisboa, v. 22, n. 85, p. 37-49, Lisboa, jan-marc., 2001.

25 VASCONCELLOS, Vinícius Gomes de. Barganha e Justiça Criminal Negocial: Análise das tendências de expansão dos espaços de consenso no Processo Penal brasileiro. São Paulo: Ibccrim, 2015, Vinicius p. 43.

26 GIACOMOLLI, Nereu José. Legalidade, oportunidade e consenso no processo penal na perspectiva das garantias constitucionais. Porto Alegre: Livraria do Advogado, 2006, p. 50.

27 VASCONCELLOS, Vinícius Gomes de. Barganha e Justiça Criminal Negocial: Análise das tendências de expansão dos espaços de consenso no Processo Penal brasileiro. São Paulo: Ibccrim, 2015, p. 55. 


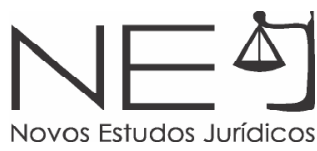

da diminuição da carga de trabalho de jogadores/julgadores públicos, além da justificativa de redução de custos de produção, e da possível emoção propiciada pelo jogo da barganha, conta com ampla adesão por parte dos agentes públicos ${ }^{28}$.

Em sendo acolhida a barganha, deve-se estabelecer quais as hipóteses de incidência e pressupostos de validade. Dito de outra forma: o que se deve ter são os requisitos e os limites legais de autorização sobre a disponibilidade do objeto da ação penal (caso penal) e o procedimento para barganha ${ }^{29}$. No sistema americano, informado por modo de pensar diverso, francamente pragmático, os limites de atuação do acusador são amplos, propiciando, com isso, a negociação do enquadramento jurídico, das sanções e dos efeitos da conduta. Isso implica em alterar, substancialmente, a maneira pela qual se está acostumado a construir verdades no processo penal, dado que o consenso retira a carga da afirmação, por decisão judicial, da efetiva ocorrência da conduta. A confirmação da conduta, para fins legais, acontece por manifestação de vontade sobre seu conteúdo, de comum acordo e chancelada pelo estado-juiz. Diante da informação (provas) amealhada, abre-se espaço para criação de um "mercado penal" em que as estratégias e táticas, moduladas pela Teoria dos Jogos, podem se fazer ver.

A equiparação dos efeitos do acordo à sentença decorrente de um processo penal tradicional implica na superação da instrução, com a exigência, todavia, de garantia dos mecanismos de formação do acordo. Por isso, deve ser: a) voluntária e informada, entendida como a possibilidade de o acusado, orientado pelo defensor, manifestar-se livre de pressões sobre as recompensas do acordo proposto, bem assim do jogador-acusador na obtenção de resultados mais breves e com a inserção de cláusulas probatórias (colaboração premiada) em face de terceiros; b) negociada e de boa-fé, em que o acervo de informações (provas e indícios) é amplamente debatido, apresentado, rejeitado, até o acordo apresentado ao juiz. Com isso, supera-se o julgamento formal, os custos e os problemas probatórios (incerteza), em nome de recompensas de ambas as partes, pelas quais a eficiência do sistema - aparentemente - estaria garantida.

28 VASCONCELLOS, Vinícius Gomes de. Barganha e Justiça Criminal Negocial: Análise das tendências de expansão dos espaços de consenso no Processo Penal brasileiro. São Paulo: Ibccrim, 2015, p. 88.

29 VASCONCELLOS, Vinícius Gomes de. Barganha e Justiça Criminal Negocial: Análise das tendências de expansão dos espaços de consenso no Processo Penal brasileiro. São Paulo: Ibccrim, 2015, p. 49. 
O "preço" da conduta atende à lógica da dissuasão e da intimidação ${ }^{30}$, na linha da análise econômica do crime, com as recompensas de cada jogador/julgador e do Sistema Penal. Tanto assim que Suprema Corte validou por diversas vezes o manejo da barganha (Brady v. United States, Santobello v. New York e Blackledg v. Allison) em face de argumentos consequencialistas de justificação, da tradição e do possível controle jurisdicional dos abusos. Prevalece, assim, a lógica da redução de custos, da noção de privilégio do direito ao processo e da liberdade do acusado e dos jogadores em buscar o ponto de acordo mais favorável a ambos, mediados pelo estado-juiz ${ }^{31}$.

O papel do juiz não é o de participar da negociação e, sim, de validar seu resultado. O controle deve ser posterior, apurando-se a prevalência da legalidade, da livre manifestação de vontade (sem pressões ou coações - físicas ou psicológicas, Suprema Corte em Brady v. United States), bem assim o conteúdo (objeto) do acordo (se há base fática). O acusado deve ter, a partir da participação de defensor, a compreensão das acusações, das consequências da barganha e dos direitos negociados ${ }^{32}$. Realizada com coação indevida ${ }^{33}$ a manifestação da vontade estará viciada e, portanto, deve-se declarar a ausência de requisito de formação do acordo.

A capacidade de negociação faz toda a diferença. Tenho um grande amigo que negocia carros. Sinto até vergonha de ir com ele na concessionária, pois a "choradeira", os "blefes", as ofertas de "pegar ou largar" parecem-me loucura. Não nasci para negociar carros. Mas posso aprender. Na última vez que estive com ele fiquei observando a maneira que se portava e indaguei, posteriormente, como sabia que o valor do veículo poderia ser baixado? Respondeu-me que os valores estão todos na "internet", mas o "trouxa", aqui, não sabia procurar. Ele tinha informação qualificada sobre os valores, as margens de lucro, bem assim o estoque de veículos - por isso tinha ido até o pátio da concessionária. Buscou

30 VASCONCELLOS, Vinícius Gomes de. Barganha e Justiça Criminal Negocial: Análise das tendências de expansão dos espaços de consenso no Processo Penal brasileiro. São Paulo: Ibccrim, 2015, p. 85.

31 Crítica consistente ao jogo da barganha: ALSCHULER, Albert. W. Implementing the criminal defendant's right to trial: alternatives the plea barganing system. University of Chicago Law Review, v. 50, n. 3, p. 931-1.050, 1983. VASCONCELLOS, Vinícius Gomes de. Barganha e Justiça Criminal Negocial: Análise das tendências de expansão dos espaços de consenso no Processo Penal brasileiro. São Paulo: Ibccrim, 2015, p. 73.

32 VASCONCELLOS, Vinícius Gomes de. Barganha e Justiça Criminal Negocial: Análise das tendências de expansão dos espaços de consenso no Processo Penal brasileiro. São Paulo: Ibccrim, 2015. p. 93.

33 VASCONCELLOS, Vinícius Gomes de. Barganha e Justiça Criminal Negocial: Análise das tendências de expansão dos espaços de consenso no Processo Penal brasileiro. São Paulo: Ibccrim, 2015. p. 91. 
inventariar as possibilidades táticas, além do que também disse para irmos mais no final do mês porque, descobri depois, o estoque precisa ser renovado.

Quem se aventura a jogar na barganha não pode ser amador. Precisa compreender sobre "Teoria de Negociação". Embora o jogador-acusador deva jogar limpo, pode acontecer de omitir provas, carregar as tintas em possíveis provas e ameaçar o acusado de uma pena maior se não acordar ${ }^{34}$. Isso faz parte das interações, mas o limite deveria ser controlado pelo estado-juiz. Entretanto, como as negociações acontecem à margem do controle jurisdicional, tornase difícil mensurar os requisitos de validade, dando azo à manipulação e ao jogo sujo. É da interação entre os jogadores que negociam informações e os benefícios que surge o termo de colaboração. Diferente do jogo de xadrez, em que todas as jogadas são previsíveis ${ }^{35}$, no Processo Penal somente da interação, do levantamento da reputação, da expectativa tática e das recompensas é que se pode estabelecer qual a estratégia no mercado da barganha. O que se pode verificar nesse contexto é a prevalência das regras de barganha próprias do mercado, como a sobrecarga penal, consistente na tática de, no início das negociações, o jogador acusador acrescentar imputações (tipos ou qualificadoras) para o fim de ter margem de negociação, bem assim sentenças "pesadas", com prisão cautelar, para o forçamento da ação delatória. O problema é que a promessa ética depende da adesão de cada jogador.

\section{A DELAÇÃO PREMIADA NÃO SIGNIFICA O PODER DA “GUERRA JUSTA”}

Quando Goldschmidt ${ }^{36}$ lançou a metáfora do processo como guerra, antecipou os vieses pelos quais se pode compreender, com maior precisão, os mecanismos de recompensa dos agentes processuais em busca de otimização pessoal, no e pelo Processo Penal. Cada sujeito processual e policial, tanto na fase pré-processual como na fase judicial, é movido por recompensas e satisfação

34 VASCONCELLOS, Vinícius Gomes de. Barganha e Justiça Criminal Negocial: Análise das tendências de expansão dos espaços de consenso no Processo Penal brasileiro. São Paulo: Ibccrim, 2015. p. 92.

35 BÊRNI, Duilio de Avila. Teoria dos Jogos: Jogos de estratégia, estratégia decisória, teoria da decisão. Rio de Janeiro: Reichmann \& Affonso, 2004, p. 13: No xadrez existe o melhor jeito de jogar e não cabe o blefe. "Assim, ao centrarmos nosso interesse na interação estratégica, já eliminamos três caminhos: o da interação sincera, o dos jogos de azar e o dos jogos que têm melhor maneira de jogar. Interessa-nos a situação em que há interação entre agentes, sendo que a ação de alguns influencia o bem-estar dos demais, e vice-versa".

36 GOLDSCHMIDT, James. Princípios Gerais do Processo Penal. Trad. Hiltomar Martins Oliveira. Belo Horizonte: Líder, 2002. 
Novos Estudos Jurídicos

de interesses particulares. Não se fala de interesses pessoais no sentido de prevaricação, embora não se exclua a hipótese. Todos querem um mundo melhor, com menos corrupção, menos crimes e, para tanto, democraticamente, estabelecem-se as regras do jogo democrático. No caso do Processo Penal brasileiro, diante da importação de novos institutos, especialmente delação e leniência, vive-se uma crise de princípios. Para além dos sistemas acusatório, inquisitório e o constitucional, atualmente, pode-se dizer que se transforma o processo penal em mecanismo de barganha, de jogo, com os riscos de trapaças, trunfos e blefes. Os institutos pensados na lógica continental deixaram de ter sentido em algumas hipóteses, especialmente na prisão cautelar. Isto porque, na teoria, a prisão cautelar deveria garantir o objeto do processo, ainda que tenha se transformado em mecanismo de pressão psicológica, midiática e patrimonial (objetiva e subjetiva) de comércio, via delação premiada. Prende-se para que crie capital para negociação, antecipando-se, assim, com os ainda não presos, possíveis negócios de informação qualificada.

Com efeito, no contexto brasileiro, o processo penal uniforme navega em frequência diferenciada, movido por recompensas distintas da apuração da verdade. A verdade, no ambiente pragmático, próprio do sistema da common law, estabelece-se por negociação. E a negociação fomenta novas modalidades de posição subjetiva. A expectativa de uma decisão favorável, como apontava Goldschmidt ${ }^{37}$, transformou-se na expectativa de uma negociação favorável, em que os advogados e membros do Ministério Público, bem assim como Delegados, precisam antecipar as jogadas, as informações qualificadas, capazes de chegar ao acordo via recompensas. O Dilema do Prisioneiro, as árvores de decisão, enfim, novos significantes precisam fazer parte do repertório.

Invoca-se o jargão da "Guerra Justa" — jus ad bellum —, executada de maneira justa - jus in bello - já que os "criminalizados" não possuem respeito pela coisa pública e, por isso, justifica-se o transpassamento dos limites herdados da modernidade. Aboliram-se as distinções entre suspeito, acusado e condenado mediante o acolhimento da figura de duas faces chamada delator. Rompem-se, por assim dizer,

37 GOLDSCHMIDT, James. Princípios Gerais do Processo Penal. Trad. Hiltomar Martins Oliveira. Belo Horizonte: Líder, 2002. 
as barreiras da presunção de não culpabilidade. Negociam-se a liberdade, a pena, a informação (prova) e, acredita-se, isso deveria ser uma questão de princípios.

A gramática processual penal exige domínios de persuasão, blefes, jogos midiáticos, vazamentos seletivos, enfim, instrumental para além de Maquiavel. Em vez de se analisar o processo, é preciso compreender o cenário do caso penal, ou seja, precisa-se apurar quem possui poder de decisão, qual a recompensa (de informações) que pretende, os alvos que busca alcançar, para somente então se poder falar de informações relevantes. A teoria da prova transmudou-se, em alguma medida, em teoria da informação qualificada. A estratégia deixou de ser meramente processual para se vincular às consequências das consequências. As coordenadas em que se pensa, portanto, o processo penal, nos casos do Processo Penal do Espetáculo, como diz Rubens Casara, exigem novos coadjuvantes. Enfrentar o jogo da mídia faz com que a defesa precise de jornalistas, detetives, especialistas, monitoramento de redes de informática, apuração de informações que possam interessar, toda uma série de dispositivos ausentes nos processos penais do dia a dia. Não se pode comparar a atuação em crimes do colarinho branco ao furto e ao roubo, pois os últimos giram noutra frequência.

Como explicar a busca e a apreensão depois da pirotecnia da realizada na casa do senador Collor? Pode-se continuar dizendo que a busca é uma medida instrumental de obtenção de provas que visa encontrar coisas e a apreensão de prova vinculada ao processo, não podendo ser um mandado aberto para apreensão de veículos emplacados? O efeito midiático, todavia, é acachapante. As fotos da apreensão, dentro das casas, dos escritórios, começaram a circular em WhatsApp antes mesmo da contagem do dinheiro e foram apresentadas, pouco depois, no Jornal Nacional. A exploração midiática satisfaz a população, tal qual os coros das tragédias gregas, que deseja espetáculo.

O limite ético deveria fazer olhar para as práticas, para nós mesmos, não justificando os fins pelos meios, especialmente quando matreiramente os meios foram legalizados e operam sem limites, muitas vezes se valendo de cláusulas abertas, desprovidas de densidade semântica. O desconforto que se opõe, todavia, reside justamente nas mentiras processuais comuns, incorporadas ao 
Novos Estudos Jurídicos

discurso ordinário, que faz com que o pensamento crítico do devido processo legal seja visto como um privilégio incompatível com a necessidade de punição. Joga-se, ademais, com um patriotismo de guerra contra corrupção que transforma qualquer um que procure colocar barreira como sendo o inimigo a ser derrotado.

Como professores de Processo Penal, talvez se tenha que promover uma mudança radical na maneira de ensinar, cientes de que as consequências das consequências podem ser complicadas, já que se está chegando ao ponto de conceder poderes não derrogatórios ao Estado em nome da guerra justa. Só não se sabe quem poderá ser o próximo inimigo. Talvez se seja fora de moda e anacrônico ou, quem sabe, romântico. E todo cuidado é pouco.

CONSIDERAÇÕES FINAIS

Em 2016, assistiu-se e participou-se, mesmo passivamente, do espetáculo do fanatismo. Entre "coxinhas" e "mortadelas", qualquer opinião proferida em artigos, palestras, enfim, nas reuniões familiares, tão logo emitida, era taxada com uma das etiquetas. Defender garantias virou sinônimo de ser favorável à corrupção, como se as questões fossem antagônicas. A simplicidade do maniqueísmo (bem x mal) cobrou o preço de diversas amizades que se desfizeram em 2016.

O desafio é pensar o jurídico e o político com certa dose de ceticismo, sem perder a esperança. Quem sabe buscar um pouco de afastamento dos juristas do embate político consiga proporcionar uma leitura de autonomia do Direito Penal, do processo penal e do momento atual do país.

Amos $\mathrm{Oz}^{38}$ argumenta que perseguir um punhado de fanáticos nas montanhas do Afeganistão é uma coisa bem distinta de lutar contra o fanatismo. Até porque o fanatismo se liga a outros motivos, nem todos racionalizáveis, a saber, inconscientes. De qualquer forma, caso não o possa findar, pelo menos se pode buscar o controle dentro de limites democráticos. Esse é o desafio. Isso porque o pensamento fanático é maniqueísta. Escolhe uma posição se fincando com total rigor em suas predileções, aniquilando todo o demais, nem sequer ouvindo os demais. O discurso é fechado em sua própria verdade (eterna), não se combinando com outros campos do social.

38 OZ, Amos. Contra o Fanatismo. Trad. Daniel Sarasola. Barcelona: Siruela, 2005. 
Giorgio Agamben, por seu turno, aponta que o poder se encontra na exceção, a saber, a possibilidade de que se exclua a regra de aplicação geral e se promova, para o caso, outra decisão. Esse poder encontra-se indicado pela estrutura, segundo a qual existe um lugar autorizado a escolher, o qual se encontra, ao mesmo tempo, dentro e fora do sistema jurídico, conforme o pensamento de Carl Schmitt ${ }^{39}$, na interseção entre o jurídico e político. Esta distinção, todavia, entre jurídico e político, precisa ser problematizada, não se podendo colocar, em absoluto, dissociados, apesar de ocuparem lugares diversos (Zizek). Neste pensar, segundo Agamben, "o estado de exceção apresenta-se como a forma legal daquilo que não pode ter forma legal"40.

Pensar desapaixonadamente o dispositivo da delação premiada foi o desafio do presente artigo, a partir das coordenadas jurídicas, em especial os requisitos à validade do negócio jurídico, apontando-se a necessidade de maiores cuidados aos delatores segregados cautelarmente, não necessariamente para considerar todas as delações de presos cautelares inválidas a priori. O que se pretendeu sublinhar é que o Direito e a normatividade devem prevalecer dentro de uma perspectiva negocial de boa-fé e de respeito às regras do jogo democrático.

\section{REFERÊNCIAS DAS FONTES CITADAS}

AGAMBEN, Giorgio. Estado de Exceção. Trad. Iraci D. Poleti. São Paulo: Boitempo, 2004.

ALSCHULER, Albert. W. Implementing the criminal defendant's right to trial: alternatives the plea barganing system. University of Chicago Law Review, v. 50, n. 3, p. 931-1.050, 1983.

ANDRADE, Roberta Lofrano. Processo Penal e Sistema Acusatório. Rio de Janeiro: Lumen Juris, 2015.

ANDREATO, Danilo. Colaboração premiada: Ato "espontâneo" ou "voluntário" do colaborador?. In: Âmbito Jurídico, Rio Grande, XI, n. 51, mar 2008. Disponível em: <http://www.ambitojuridico.com.br/site/ index.php?n_link=revista_artigos_leitura \&artigo_id=4620>. Acesso em mar/2016.

BADARÓ. Gustavo. Quem está preso pode delatar? 2015. Disponível em: http://jota.uol.com. br/quem-esta-preso-pode-delatar. Acesso em: mai/2016. 
BÊRNI, Duilio de Avila. Teoria dos Jogos: Jogos de estratégia, estratégia decisória, teoria da decisão. Rio de Janeiro: Reichmann \& Affonso, 2004.

BITTAR, Walter Barbosa. Delação premiada: direito estrangeiro, doutrina e jurisprudência. Rio de Janeiro: Lumen Juris, 2011.

BOFF, Leonardo. Prefácio. In: EYMERICH, Nicolau. Manual dos inquisidores. Trad. Maria José Lopes da Silva. Rio de Janeiro: Rosa dos Tempos; Brasília: Fundação Universidade de Brasília, 1993.

BRITO, Michelle Barbosa de. Delação Premiada: da eficiência à integridade. Belo Horizonte: Editora D'Plácido, 2016.

CADEMARTORI, Sérgio. Estado de Direito e Legitimidade: uma abordagem garantista. Porto Alegre: Livraria do Advogado, 1999.

CARVALHO, Thiago Fabres de; MORAIS DA ROSA, Alexandre. Processo Penal eficiente e ética da vingança: em busca de uma criminologia da não violenta. Rio de Janeiro: Lumen Juris, 2010.

CHEMIN, Rodrigo. Mãos Limpas e Lava Jato: a corrupção se olha no espelho. Porto Alegre: CDG, 2017.

COPETTI NETO, Alfredo. A democracia constitucional sob o olhar do garantismo jurídico. Florianópolis; Empório do Direito, 2016.

COSTA, Eduardo Maia. Princípio da oportunidade: muitos vícios, poucas virtudes. In: Revista do Ministério Público de Lisboa, v. 22, n. 85, p. 37-49, Lisboa, jan-mar., 2001.

CUNHA, Rogério Sanches; PINTO, Ronaldo Batista. Crime Organizado: Comentários a nova lei sobre o crime organizado - Lei n 12.850/2013. 2. ed. Salvador: Jus Podivm, 2014.

DIAS, Pamella Rodrigues da; SILVA, Erik Rodrigues. Origem da delação premiada e suas influências no ordenamento jurídico brasileiro. Disponível em: http://rafael- paranagua. jusbrasil.com.br/artigos/112140126/origem-da-delacao-premiada-e-suas-influencias-noordenamento-juridico-brasileiro. Acesso em: maio 2016.

D'URSO, Luiz Flávio Borges. Delação premiada - proibição para quem está preso. 2015. Disponível em: http://politica.estadao.com.br/blogs/fausto-macedo/delacao-premiadaproibicao-para-quem-esta-preso/. Acesso em: mai/2016.

FERNANDES, Antonio Scarance. Processo Penal Constitucional. 7. ed. São Paulo: Revista dos Tribunais, 2012.

FERRAJOLI, Luigi. Derechos y garantías. - La ley del más débil. Trad. Perfecto Andres Ibanez. Madrid: Trotta, 1999. 
. Derecho y razón. Trad. Perfecto Andres Ibanez. Madrid: Trotta, 2001.

. Los fundamentos de los derechos fundamentales. Trad. Perfecto Andres Ibanez. Madrid: Trotta, 2001.

. Direito e Razão: teoria do garantismo penal. Trad. Ana Paula Zomer et alii. São Paulo: Revista dos Tribunais, 2002.

Garantismo: una discusión sobre derecho y democracia. Trad. Andrea Greppi. Madrid: Trotta, 2006;

GAGLIANO, Pablo Stolze. Novo curso de direito civil, volume 1: parte geral. 14. ed. São Paulo: Saraiva, 2012.

GIACOMOLLI, Nereu José. Legalidade, oportunidade e consenso no processo penal na perspectiva das garantias constitucionais. Porto Alegre: Livraria do Advogado, 2006.

GOLDSCHMIDT, James. Princípios Gerais do Processo Penal. Trad. Hiltomar Martins Oliveira. Belo Horizonte: Líder, 2002.

GRADIS, Rodrigo de. Prisão não invalida a delação premiada. 2015. Disponível em: http:// jota.uol.com.br/rodrigo-de-grandis-prisao-nao-invalida-a-delacao-premiada. Acesso em: maio/2016.

GRECO FILHO, Vicente. Comentários à Lei de Organização Criminosa: Lei n. 12.850/13. São Paulo: Saraiva, 2014.

JESUS, Damasio de. Perdão Judicial - colaboração premiada análise do art. 13 da Lei 9.807: primeiras ideais. Boletim IBCRIM. São Paulo, v. 7. N. 82, set. 1999.

LEAL, João José. A Lei 9.807/99 e figura do acusado-colaborador ou prêmio à delação. RT/ Fascículos Penais, s.1, ano 80, v. 782, pp. 443-458, dez. 2000.

LEAL, Magnólia Moreira. A delação Premiada: um questionável meio de provas frente aos princípios e garantias constitucionais. 2012. Disponível em: http://www.jurisway.org.br/v2/ dhall.asp?id_dh=7663. Acesso em: abr/2016.

LESCANO, Mariana Doernte. A delação premiada e sua (in) validade à luz dos princípios constitucionais.

LOPES JR., Aury. Direito Processual Penal. 9a . ed. São Paulo: Saraiva, 2012.

LOPES JR., Aury; ROSA, Alexandre Morais da. Limite penal: No jogo da delação premiada, prisão cautelar é trunfo fora do fair play. 2015. Disponível em: http://www.conjur.com. br/2015-ago-07/limite-penal-jogo-delacao-prisao-cautelar-trunfo-fora- fair-play. Acesso em: mai/2016. 
LÓPEZ MEDINA, Diego Eduardo. La teoria impura del derecho. Bogotá: Legis, 2004.

MAIEROVITCH, Wallter Fanganiello. Apontamentos sobre Política Criminal e a "Plea Bargaining". Revista de Processo, ano 16, n. 62, abr./jun. 1991. p. 91-96.

MARCELLINO JR, Júlio. MORAIS DA ROSA, Alexandre. O Processo Eficiente Na Lógica Econômica: Desenvolvimento, Aceleração e Direitos Fundamentais. Florianópolis: Empório do Direito, 2015.

MENDES, Marcella Sanguinetti Soares. A delação premiada com o advento na Lei 9.807/99. In: Âmbito Jurídico, Rio Grande, XV, n. 98, mar 2012. Disponível em: <http://www.ambitojuridico.com.br/site/?n_link=revista_artigos_leitura\& artigo_id $=11229 \&$ revista_caderno $=3>$. Acesso em: mar 2016.

MORAIS DA ROSA, Alexandre. Guia do Processo Penal conforme a Teoria dos Jogos. 4. ed. Florianópolis: Empório do Direito, 2017.

. Para entender a delação premiada pela teoria dos jogos: táticas e estratégias do negócio jurídico. Florianópolis: Empório Modara, 2017.

MOSSIN, Heráclito Antonio; MOSSIN, Júlio Cesar O.G. Delação Premiada - aspectos jurídicos. Leme: J.H.Mizuno, 2016.

NICOLÁS GARCÍA, Gerardo; ALBERTO JULIANO, Mario; PÉREZ GALIMBERTI, Alfredo. Derecho al mejor derecho y poder punitivo. Buenos Aires: Del Puerto, 2011.

OZ, Amos. Contra o Fanatismo. Trad. Daniel Sarasola. Barcelona: Siruela, 2005.

POSNER, Richard A. A economia da justiça. São Paulo: WMF Martins Fontes, 2010.

PRADO, Geraldo. Transação Penal. Coimbra: Almedina, 2015.

. Poder Negocial (sobre a pena), Common Law e Processo Penal Brasileiro: Meta XXI, em busca de um milhão de presos! In: BONATO, Gilson (Org.). Processo Penal, Constituição e Crítica: estudos em homenagem ao Dr. Jacinto Nelson de Miranda Coutinho. Rio de Janeiro: Lumen Juris, 2011, pp. 299-316.

RAMOS, João Gualberto Garcez. Curso de processo penal norte-americano. São Paulo: RT, 2006.

ROBLES, Gregorio. As regras do direito e as regras dos jogos: ensaio sobre a teoria analítica do direito. Trad. Pollyana Mayer. São Paulo: Noeses, 2011.

SARLET, Ingo Wolfgang (org.). Dimensões da dignidade: ensaios de filosofia do direito e direito constitucional. Trad. Ingo Wolfgang Sarlet, Pedro Scherer de Mello Aleixo e Rita Dostal Zanini. Porto Alegre: Livraria do Advogado, 2005. 
SCHÜNEMANN, Bernd.¿Crisis del procedimiento penal? ¿ Marcha triunfal del proceso penal norte-americando en el mundo? In: SCHÜNEMANN, Bernd. Temas actuales y permanentes del derecho penal después del milênio. Madrid: Tecnos, 2002, p. 288-302.

VALE, Ionilton Pereira do. Teoria Geral do Direito Processual Penal: estudo unificado com a doutrina e a jurisprudência do Supremo Tribunal Federal e do Superior Tribunal de Justiça. Rio de Janeiro: Lumen Juris, 2015.

VASCONCELLOS, Vinícius Gomes de. Barganha e Justiça Criminal Negocial: Análise das tendências de expansão dos espaços de consenso no Processo Penal brasileiro. São Paulo: Ibccrim, 2015.

ZACLIS, Daniel. A voluntariedade na delação premiada. 2015. Disponível em: http:// painelacademico.uol.com.br/painel-academico/4572-a-voluntariedade-na-delacaopremiada. Acesso em: mai/2016.

Recebido em: 10/02/2019

Aprovado em: 20/04/2019

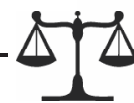

